\title{
Business Ethics in Price Discrimination in the Automotive Industry \\ Yizhe $\mathrm{Wu}^{1, a,{ }^{*}}$, Xingjian Wang ${ }^{2, b}$, Danni Shen ${ }^{3, \mathrm{c}}$ 1.2.3 Hangzhou No.14 High School AP Center, China

\author{
a,*wuyizhe302@sina.com, b62397416@qq.com, c2832357072@qq.com
}

\begin{abstract}
Keywords: Business Ethics, Price Discrimination, Automobile Industry, Chinese and Foreign Comparison
\end{abstract}

\begin{abstract}
There is a huge price difference between Chinese and foreign car prices. The gap of price between different models is different. There is price discrimination behind it and harms the interests of domestic consumers. At the same time, there is business ethics behind such price discrimination. The monopoly, asymmetric information, imperfect laws and regulations, and difficulties in government supervision have led to the problem of business ethics in price discrimination, which can be solved by strengthening corporate self-discipline, social supervision, government oversight and Improving relevant laws and regulations.
\end{abstract}

\section{Introduction}

Globalization makes optimal allocation of resources and production, which makes costs continue to decrease. However, in China's rich labor market and overall low prices, the price of cars is higher than that of the United States, and so on, which is worth our attention and reflection. If there is a price discrimination, it will increase the profits of the company at the expense of consumers. Business ethics is indispensable for companies to correctly understand and handle its roles, functions, responsibilities and obligations in society and the market. Is there business ethics behind price discrimination?

\section{The Price Differences between Chinese and Foreign Automotive Industry}

There is a common misunderstanding of the difference between domestic and foreign car prices.

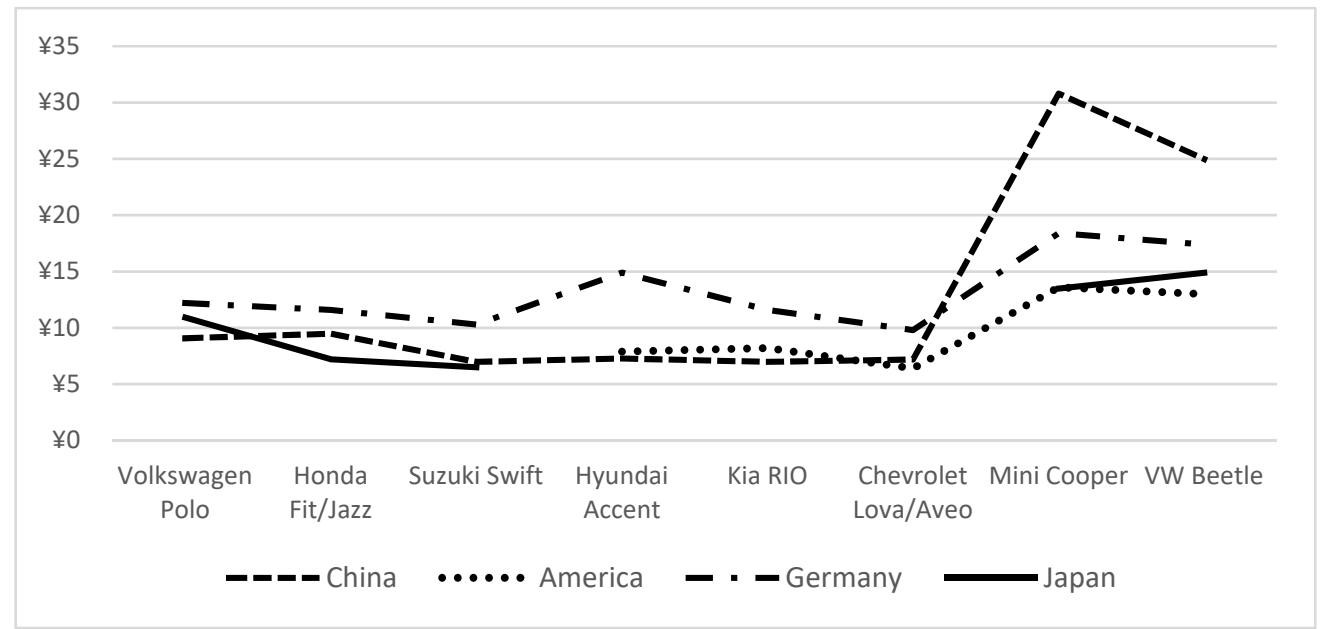

Figure 1.Comparison of small cars in various countries 


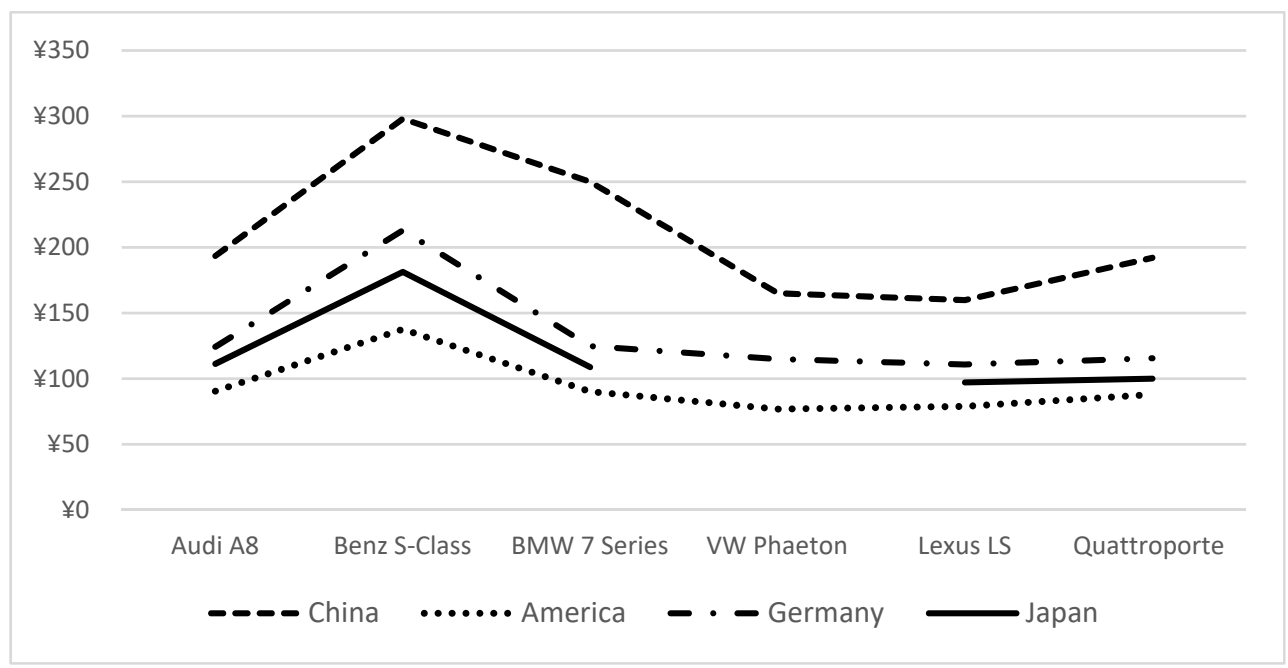

Figure 2.Comparison of luxury models in different countries

That is, the price of new cars in foreign is higher than that in China. In order to understand more clearly the differences in the prices of Chinese and foreign cars, we classify cars according to their models, compare and analyze different models in different countries. As shown in fig. 1 and fig. 2 , in the compact and small car categories, except for the purely imported Mini Cooper and VW Beetle, the prices of most domestic cars are actually cheaper and more competitive than most European and American countries, the price of medium-sized cars is generally 50-100 thousand higher than abroad. The biggest difference in price is in large-scale cars and luxury models, the domestic selling price is basically double the price of European and American countries.

\section{Price Discrimination and Business Ethics}

\subsection{The Concept of Price Discrimination and Business Ethics}

Price discrimination is a pricing strategy that charges different prices to customers of the same product or service. In pure price discrimination, the seller charges each customer the highest price he is willing to pay. In the more common forms of price discrimination, sellers place customers in groups based on certain attributes and charge different prices for each group [1].According to the definition of price discrimination, we can find that all the above-mentioned differences as price discrimination.

Business ethics (known as corporate ethics) is a form of applied ethics that examines the moral principles and moral or ethical issues that arise in the business environment [2]. Business ethics is used to guide business and help these companies maintain better relations with their stakeholders.

\subsection{First Degree Price Discrimination and Business Ethics}

The first-degree price discrimination is also called full price discrimination. It refers to the manufacturer's differential pricing of products based on the highest price among different consumers in order to maximize their profits. Take the luxury car as an example, excluding the impact of taxation, the pricing of the BMW 730 in China is still more expensive than that in America. Because the highest price for domestic buyers is higher than that in America, the seller has increased the domestic price on this basis. This behavior of manufacturers is a violation of business ethics, because car companies distinguish people based on their own choices and price tags to get their most profitable things.

\subsection{Second Degree Price Discrimination and Business Ethics}

In second degree price discrimination, price varies according to quantity demanded[3]. In this situation, although manufacturers will get marginal revenue based on volume, we do not think that this is a problem of business ethics, because when manufacturers receive marginal revenue, customers will also benefit from changes in volume. 


\subsection{Third Degree Price Discrimination and Business Ethics}

Third degree price discrimination, means charging a different price to different consumer groups [3]. In this type of price discrimination, there are two types of situations, different market price discrimination and different timing of price discrimination. For example, the Benz S-Class sells for 2.98 million in China and 1.376 million in American. We find that Mercedes-Benz manufacturers still impose price discrimination on Chinese and foreign markets even if they exclude the impact of taxation rates, this is the price discrimination in different markets. The price discrimination caused by non-simultaneous is that auto manufacturers adopt different pricing strategies at different times. This is also an unfair behavior for customers, which is also within the business ethics.

\section{Reasons of Business Ethical Problems in Price Discrimination}

\subsection{Monopoly}

The auto industry has a monopoly of model, function, technology, etc. Due to the uniqueness of the technology, auto manufacturers can raise prices arbitrarily. For example, Lamborghini's turbocharged technology, Tesla's autonomous driving technology and proprietary technologies have led to a degree of monopoly, which is certainly a matter of business ethics.

\subsection{Information Asymmetry}

Due to the information asymmetry between consumers and auto companies, imported car manufacturers rely on the dominant position of the market and hinder the communication channels to control prices and profits. Moreover, because the cost of manufacturing false information is extremely low, companies can take the opportunity to increase false circulation costs and implement high prices in countries with high taxes. This is clearly an unethical violation of business ethics.

\subsection{Incomplete Laws and Regulations}

Although China has laws and regulations prohibiting price discrimination, its scope of application is limited to its territory. International laws also lack relevant provisions that limit transnational price discrimination. Therefore, under the current legal system framework, it is necessary to treat multinational companies in different countries. The regulation of price discrimination between two countries is actually in a situation where it has no law to rely on [4].

\subsection{Difficulty in Government Supervision}

Due to the difficulties in the definition of price discrimination and the uncertainty in the results of price discrimination benefits, it is hard for government to supervise. Firstly, only the manufacturer knows the difference in the cost of the products or services it provides; secondly, government can take interventions to force monopolies to reduce monopoly profits, but consumers is not sure to benefit from it.

\section{Countermeasures to Solve Business Ethical Problems in Price Discrimination}

\subsection{Strengthen Corporate Self-Discipline}

Under the current social and cultural conditions, a company that is in conflict with society and the environment will not have a fancy prospect. Companies can restrict themselves by selecting ethical employees, setting ethical goals, formulating and implementing corporate ethics codes, promoting ethical construction at senior levels, and strengthening corporate ethics education for employees to address the emergence of business ethical problems in price discrimination [5].

\subsection{Strengthen Social Supervision}

The main body of social supervision is stakeholders, social organizations and news media. The supervision of stakeholders, including the competitors, partners, makes each company's behavior more ethical through the supervision of each other. Social organizations can establish official, 
industry or non-governmental organizations to supervise enterprises. Using mass media to condemn the company's wicked acts, can also produce a huge effect of public opinion.

\subsection{Strengthen Government Supervision}

On the one hand, the government can issue relevant policies and regulations to regulate automobile companies and publish some necessary data to improve the definability of price discrimination; on the other hand, it can design a new kind of Variable Levy, the International Automobile Trading's Variable Levy, reducing the traditional tariff and transferring it to $30 \%$ to $80 \%$ of the international automobile trade variable levy according to the price difference.

\subsection{Improve Relevant Laws and Regulations}

Legal supervision can forcefully determine the value orientation of corporate behavior and help to quickly reverse corporate behaviors. The Chinese government should apply more policies, laws and regulations on anti-monopoly. Since the auto companies with price discrimination studied in this paper are all global enterprises, the World Trade Organization should also introduce more perfect policies to regulate the marketing methods of auto companies.

\section{Summary}

We can't generalize that all price discrimination is a matter of business ethics. The price difference caused by the actual costs in the three types of price discrimination is not a problem of business ethics. After eliminating interference factors, there are still business ethical problems in price discrimination. We can force companies to abide by business ethics through strengthening corporate self-monitoring, social supervision, government supervision, and improving laws and regulations. But the realization of corporate ethical behavior ultimately depends on specific individual actors. Therefore, the key to solving business ethical problem in the auto industry lies in the degree of corporate own pursuit of ethical behavior.

\section{References}

[1] Robert Phillips, Pricing and Revenue Optimization, Stanford University Press, p74, 2005.

[2] Ikbale Totaa, Hidajet Shehua, The Dilemma of Business Ethics, Procedia Economics and Finance, No.3, pp555-559, 2012.

[3] Sylvain Weber, Cyril Pasche, Price Discrimination, Journal of Industrial Organization Education, Vol.2, No.1, pp1-15, 2009.

[4] Wu Yongtao, Zhangqun, Multiple Price Discrimination Features for Selecting Tariffs Selectable, Mathematics Practice and Understanding, pp588-595, 2002.

[5] Stephen P. Robbins, Mary Coulter, Management, China Renmin University Press, p135, 2012. 